\title{
Quality Parameters of 3D Print Products by the DMLS Method
}

Karel Dvorak, Lucie Zarybnicka, Jana Dvorakova

College of Polytechnics Jihlava, Department of Technical Studies. Tolstého 16, 58601 Jihlava. Czech Republic. E-mail: karel.dvorak@vspj.cz, lucie.zarybnicka@vspj.cz, jana.dvorakova@vspj.cz

\begin{abstract}
Additive technologies are a dynamically evolving category of manufacturing methods for a wide range of industries, particularly engineering and related fields. Compared to traditional technologies based on chip machining, molding and casting, they offer new production options, particularly for complex shape components. At the same time, however, there are differences and limits that must be taken into account when designing functional machine parts. The important quality parameters of the products are in particular the dimensions and the quality of the surface. These factors are of fundamental importance for the subsequent assembly and function of a component in a plant assembly. They determine, together with the structural material properties, the usability of the component and the economic efficiency of the production in order to achieve the finished product with the minimum need for postprocessing the finished part. The submited text presents the results of the quality parameter research carried out on 3D print products made by the DMLS method, where the focus is put on the assessment of linear dimensions and the surface quality of samples from three selected materials and a combination of two print modifications. The measurement results are compared to generally valid standards and tabulated values to verify and eventually modify table values for use when designing a design solution with the use of 3D print products.
\end{abstract}

Keywords: Aditive Manufacturing, Digital Model, Dimensions, Surface quality, Roughness

\section{Introduction}

Production technologies, based on material additions or changes in material structure, undergoe dynamic development. Production technologies are available and product quality is getting closer to the quality of products produced by traditional manufacturing technologies. The deployment of traditional technologies is determined from the functional point of view by the attainability of the required dimensional and shape parameters of a component with defined material properties specific to the particular method. Other factors for application of the production technology are the economic aspects based on the availability of the production equipment and the cost of production for the required number of products. The current design trend is based on the creation of a 3D digital model of components - a virtual prototype, which is the starting point for creating production documentation, conducting simulations, creating virtual assemblies of equipment and preparing production technology. The advantage of additive technologies is the rapid preparation of the postprocessor by defining the production parameters according to the used method and technological specification of the equipment. Typically, no specific tools and preparations are required. An advantage is a relatively rapid acquisition of prototype samples of complexly shaped products. Traditional production processes, based on machining, forming and casting, are going through a longer history of research and experience. It is possible to assess more accurately the technological and economic demands on the production of a component with defined functional parameters. Additive technologies, despite being well thought out when designing component solutions, are undergoing a series of research studies based on the exact measurement of selected parameters and on the evaluation of the experience from the operation of such parts [1]. The results of the measurements on the groups of metal samples produced by the DMLS method are evaluated in the present text. The groups are divided according to the material and the modification of the production, always on the same device. The selected measured parameters are linear dimensions and surface quality.

\section{DMLS Method}

This is a $3 \mathrm{D}$ printing method by sintering a metallic material in the form of powder by a laser beam. The material is applied in layers as described in [2]. The beam path in XY direction of the horizontal plane is determined by the sectional area of the printed part. Sequence of cuts of defined thickness determines shape and dimensional characteristics in $\mathrm{Z}$ direction - vertical direction. The planar characteristics of the cuts in the plane in combination with the spatial characteristics of the individual joined cuts determine the overall quality parameters of the printed object - the engineering components:

- Dimensional accuracy,

- Surface quality,

- Shape accuracy,

- $\quad$ Structural properties - Strength and flexibility.

The above characteristics are relevant for the functional use of the component as a separate component or assembly component. At the same time, they are the starting point for any subsequent technological adjustments, usually to achieve greater precision of defined functional dimensions [3]. The objective of increasing the efficiency of the production processes of the components is to define the optimal technological conditions of the production operation with the minimal necessity of subsequent postprocessing. The advantage of additive technologies when compared with, for example, machining on a multi-axis machining machine is to achieve complex free formed shapes based on the principle of the method. Machining 
limits are determined by tool and cutting characteristics in combination with mechanical and control features of the machine. However, at the specified dimensions, it is possible to achieve a high degree of accuracy and surface quality with adhering to the technological conditions, without the need for subsequent adjustment procedures. When designing a functional part produced by the machining method or by some other conventional methods (casting, forming), it is also possible to consider the defined structural properties corresponding to the starting material or defined by a change in the structure by thermal or forming treatment. Another factor that determines the productive usability of a given method is productivity. This factor is particularly important for serial and mass production [4]. From this point of view, currently available additive technologies can not be considered as productive. Production times are determined by the size and shape of the printed part, and optimization options are the subject of ongoing research. Additive technologies are primarily designed for the production of prototypes and small series, where part of the productivity is the time required for the technical preparation of the component production, the preparation of specific tools and the configuration of the production equipment [5]. In the above-mentioned cases, the times required, particularly for complex components, may be considerably shorter, which, compared to other conventional technologies, can bring the advantage of a quick disposition of the component [6]. By analyzing fixed and variable costs, it is possible to determine the suitability of deploying a particular manufacturing technology for a given component. This is multifactor analysis with multiple input variables. In order to increase the validity of calculations of the efficiency of production technology deployment, the set of input factors also includes the resulting quality parameters of the manufactured component, determining its functional use in subsequent life cycle phases. By analyzing the principles of the DMLS method, the achievable accuracy of printing of machine parts within a given range of dimensions and specific surface characteristics can be classified as significant input factor. The results of the research of these characteristics on the defined samples are the subject of a research survey, the results of which are shown in the presented text.

\section{Technical preparation of the 3D printing model}

The starting point for 3D print is a $3 \mathrm{D}$ digital model. A 3D digital model can be obtained by using any of these methods for practical use:

- 3D scan of a real part,

- Modeling in a 3D CAD application,

- Combining both methods above.

For the technical preparation of production of a quality engineering component we assume the primary use of the design in the 3D CAD application, where it is possible to take into account the characteristics of the chosen method of production already by the creation of a model. The 3D scan method provides primary data, limited by the characteristics of the device being used, in conjunction with other factors. Additional modeling based on scanned data may be difficult and overcome the primary modeling process. A primarily created parametric model is the bearer of a wide range of information [7]. In addition to precisely defined dimensional and shape characteristics, it is possible to define the structural characteristics according to the material, to perform the basic diagnostics and, in relation to the production technology, the corresponding correction, usually on an associative copy. In particular, additive technologies require dimensional corrections to achieve the required accuracy of the functional dimension without the need for subsequent postprocessing. The default $3 \mathrm{D}$ model is also a draft for the drawing documentation, creating a virtual assembly, and performing simulations based analysis. The advantage of a parametric model where each dimension is saved as a variable is also the ability to edit the model via an external interface, which extends the capabilities of development and research activities without the need for a CAD application. Non-parametric models can be edited using the Direct Modeling method in the CAD tool, which is a major factor in preparing a 3D print model using a universal data transfer format, eg across CAD applications from different providers, or processing a model on an external customer model by removing customer parameters limiting the availability of design know-how, without limiting the reach of technological results. The basic tool for modeling is the modeling tool - CAD. The created model can be used to create drawing documentation and virtual assembly. Using a calculation and simulation tool - CAE, the appropriate structural or fluid simulation can be performed on the model to verify and predict the behavior of the component during its operation. The input parameters can also be the measurement results, imported into the tool and used to verify the subsequently created functional component. An important factor related to 3D printing is the topological optimization of the model, where the expected differences in the structural characteristics of the $3 \mathrm{D}$ print product and the defined marginal load conditions of the component allow the optimization of the technology by suitable orientation of the printing model relative to the machine coordinate system [8]. The samples used for the research survey presented in the text are made by the DMLS method from three different types of material where the output is a primary volume model. It should be noted here that modeling tolerances in practice of commonly used CAD tools are orderly smaller than manufacturing tolerances of commonly available manufacturing technologies [9]. The direction of application of the layers is illustrated in Figure 1. Two variants of the model are tested, where in one case the layers are parallel to the axis of the model, according to the drawing, in the second case the layers are applied at an angle of 45 degrees with respect to the axis of the model. 

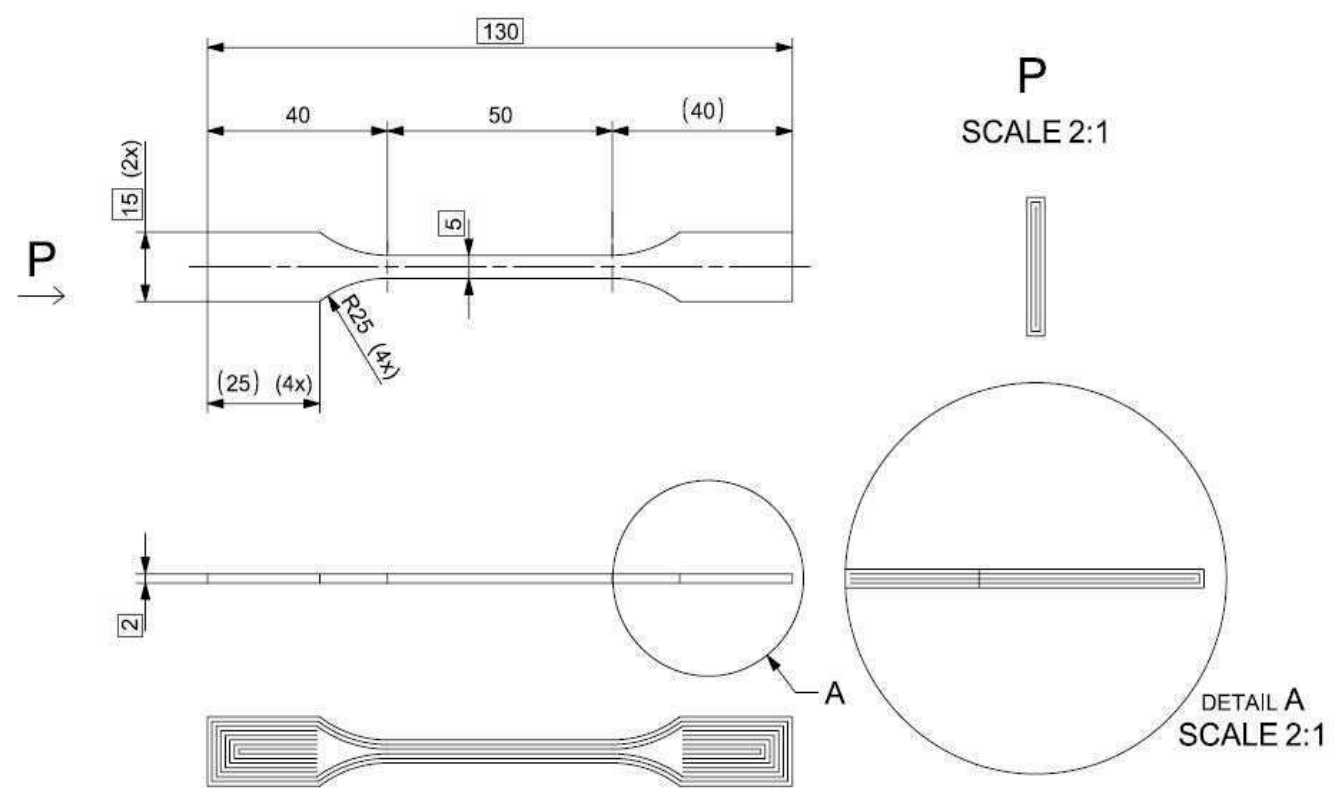

SCALE 2:1
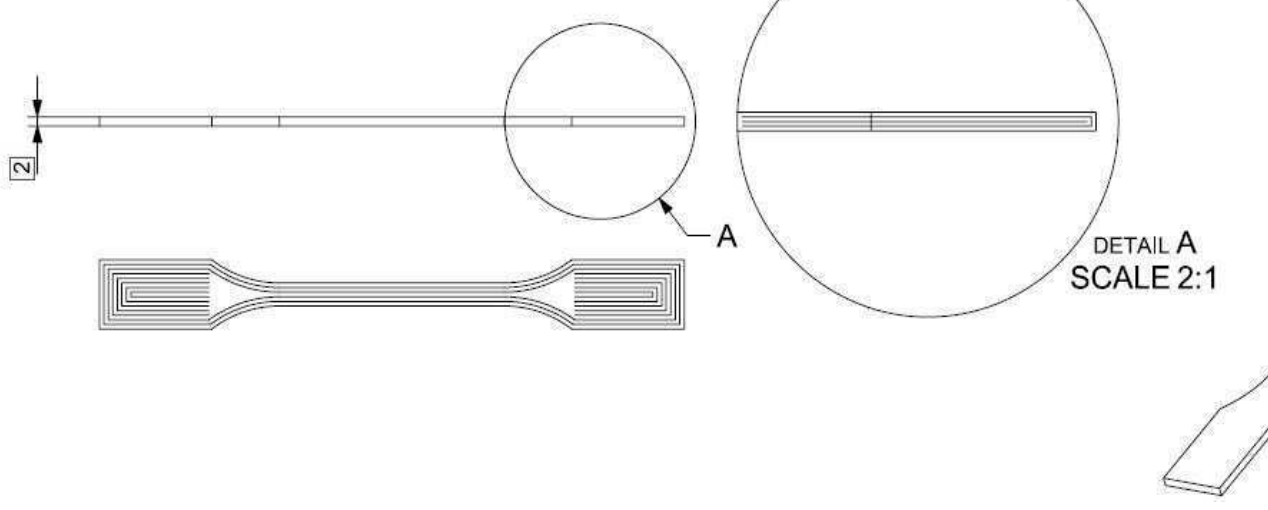

Fig. 1 Test Bar Drawing with assigned tested dimensions

\section{Dimensional characteristics of samples}

For analysis, samples are used in the form of standard bars designed for the tensile test. The characteristics are tested on the linear dimensions shown in the drawing. The drawing is a document for information for 3D printing. The main source of information is a $3 \mathrm{D}$ model, which also serves as a basis for drawing. Measurement is performed manually, with a micrometer, longer linear dimensions with a sliding scale with a nonionic scale resolution of $0.02 \mathrm{~mm}$. The results of the measured values with an indication of the relevant dimension in the drawing of Fig.
1 are given in Tab. 1. The statistical evaluation is a part of Table 2. The reference for determining the measurement deviation and the total error is the interval corresponding to the accuracy of ISO 2768 - c. The stated accuracy is declared for the production of DMLS technologies on the EOSINT M270 / 290 machine. For the measured values, the conformity with the accuracy in the tolerance degree $\mathrm{m}$, which can be considered the most widespread, is tested at the same time. The norm for dimensions of length in the given precision lists the deviations shown in Tab. 1 in $\mathrm{mm}$, used for the size range of the tested samples:

Tab. 1 Permissible tolerances of unattended dimensions according to the declared accuracy of the printing method

\begin{tabular}{|c|c|c|c|c|c|c|}
\hline Designation & Title & 0.5 to 3 & Over 3 to 6 & Over 6 to 30 & Over 30 to 120 & Over 120 to 400 \\
\hline m & medium & \pm 0.1 & \pm 0.1 & \pm 0.3 & \pm 0.5 & \pm 0.8 \\
\hline $\mathrm{c}$ & coarse & \pm 0.2 & \pm 0.3 & \pm 0.5 & \pm 0.8 & \pm 1.2 \\
\hline
\end{tabular}

Tab. 2 Overview results of statistical evaluation of sample set

\begin{tabular}{|l|c|c|c|c|c|c|}
\hline \multicolumn{1}{|c|}{ Material / method } & Weight & Length & Width & Thicken & s2_1 & s2_2 \\
\hline $\begin{array}{l}\text { M270 STAINLESS } \\
45^{\circ} \text { MS1/0,040 }\end{array}$ & 18.57 & 130.76 & 4.96 & 2.02 & 14.97 & 15.04 \\
\hline $\begin{array}{l}\text { M270 STAINLESS } \\
\text { HORIZONTAL } \\
\text { MS1/0,040 }\end{array}$ & 18.83 & 130.10 & 5.13 & 2.03 & 15.17 & 15.16 \\
\hline $\begin{array}{l}\text { M290 MS1/0,050 } \\
\text { 45 MARTENZIT }\end{array}$ & 20.17 & 129.85 & 5.04 & 2.09 & 15.07 & 15.7 \\
\hline $\begin{array}{l}\text { M290 MS1/0,050 } \\
\text { H0RIZONTAL } \\
\text { MARTENZIT }\end{array}$ & 20.21 & 129.85 & 5.03 & 2.08 & 15.03 & 15.03 \\
\hline $\begin{array}{l}\text { IN718 } \\
\text { HORIZONTAL } \\
\text { M290 }\end{array}$ & 19.48 & 130.27 & 5.06 & 2.06 & 15.16 & 15.16 \\
\hline
\end{tabular}


Samples are measured by material in each of the two print orientations relative to the sample axis. Other printing conditions are the same. The results of the measurements are shown after the statistical processing in tab. No. 2 and subsequently interpreted. The measurement is carried out in constant laboratory conditions by a multiple, calibrated micrometer. Linear dimensions are selected, the measurement of which does not require the use of any other jigs. The measurement method is chosen with respect to the anticipated subsequent workshop use of 3D print products for assembly use or subsequent processing. The aim of the measurement is to verify the reliability of the achieved accuracy for the proposal of the design solutions and the production without the necessity of postprocessing.

Further conclusions can be drawn from the statistical evaluation. The highest match of precision is found in the Maraging Steel 1.2709 tool steel. All measured samples conform to the declared tolerance of dimensions in degree of accuracy c. When assessing the tolerance matches in the precision level, m satisfies only the smallest dimension representing the thickness of the samples. In the sample length parameter, according to ČSN ISO 2687, samples of stainless steel 1.4542 printed at an angle of $45^{\circ} \mathrm{do}$ not comply with the accuracy class $\mathrm{m}$. In the sample width parameter, according to CSN ISO 2687, samples with the top layer of tool steel 1.2709 printed horizontally do not comply with the accuracy class $\mathrm{m}$. It can be deduced from the aforementioned that the production position in $3 \mathrm{D}$ printing plays a significant role in achieving the required accuracy with respect to the material applied by this method in the layers. The importance of the positon of layers in $3 \mathrm{D}$ printing was also described in [10]. Taking into account this influence is important for determining the orientation of the printing model during production in accordance with the requirement to achieve the accuracy of one of the dimensions of the part. An alloy with high nickel content, Inconell 718 complies with the degree of accuracy $\mathrm{m}$ in all measured sizes.

\section{Properties of samples}

Surface properties are tested on the test specimen surfaces. Declared production quality of the surface is Ra $10.0-12.5$. Surface properties are tested using 3D digital microscopic measurement with visualization. An example of a 3D Surface Print Surface Structure for Stainless Steel 1.4542 in 200x magnification is shown in Figure 2.

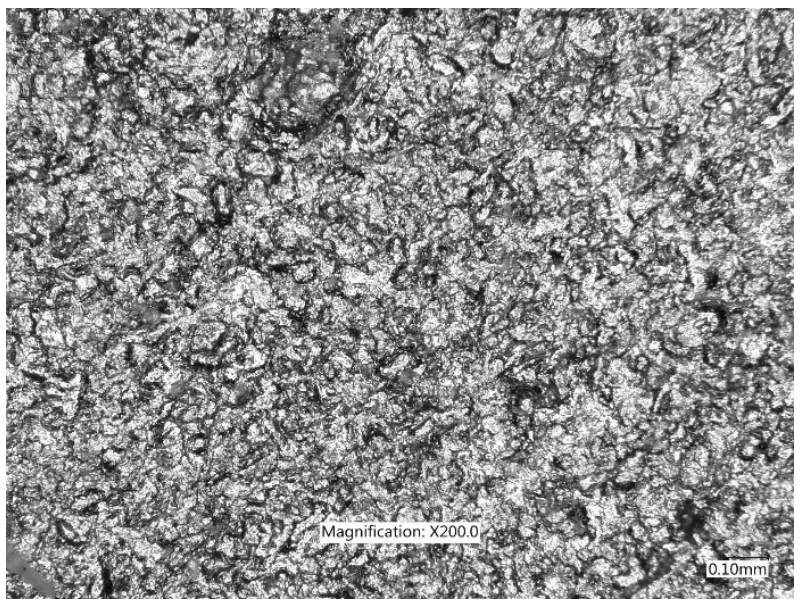

Fig. 2 Surface of $3 D$ printed sample

The digital evaluation of the measured surface with the visualization of inequalities through the colored spectrum is shown in Figure 3. The 3D surface visualization of the sample cutout provides an overview of the regularity of the distribution of inequalities and the homogeneity of the surface properties.

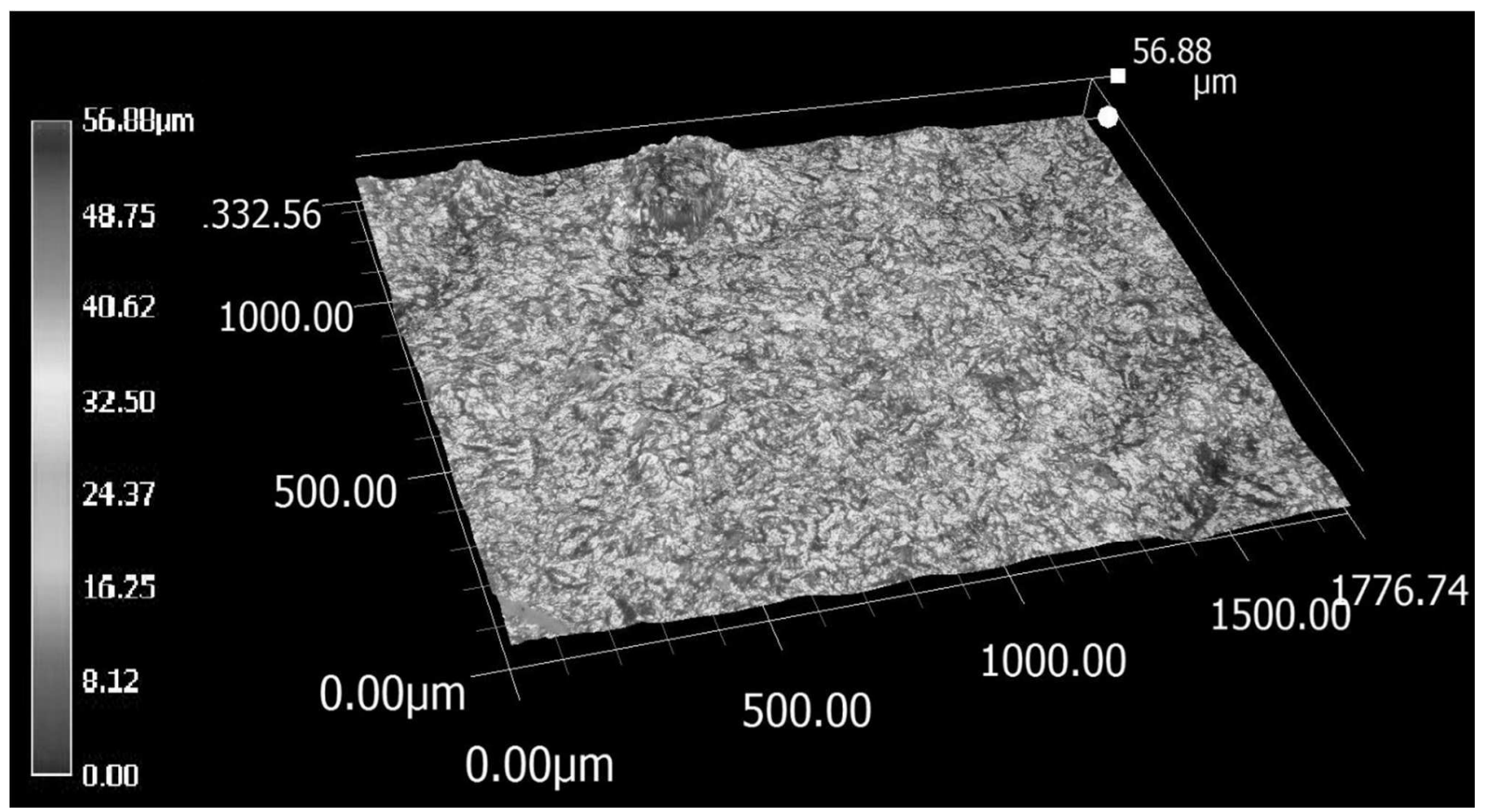

Fig. 3 Surface digital spectrum of $3 D$ printed sample M270, $45^{\circ}$ 
Homogeneity of distribution in the global spectrum does not provide direct information on technically usable surface quality, defined by the mean height of inequality. This parameter is labeled $\mathrm{Ra}$ and determines the technical usability of the functional areas of the component. Global distribution of the spectrum is important especially in the case of the significance of specific parameters of the structure, which is typical for, for example, chip-machined surfaces, where the marks of the tool are defined. The defined quality of the surface in combination with the machining direction is an important characteristic especially for defining sealing surfaces for rubber, plastic, copper or aluminum seals. The heterogenous microstructure of printed materials is described also in [11]. It differs eg. from selective laser melting (SLM) as described in
[12]. The mentioned problem of DMLS is solved especially in the context of vacuum-technical 3D printing by the DMLS method with a specific homogeneous distribution of inequalities. The slope of the printed part does not affect the distribution of the inequalities and does not provide the characteristics specific to the chip machining areas. Following series of images represents evaluated measurement visualization for selected materials printed using the same method. The materials are the same as in the previous chapter and each measurement is further performed for horizontal orientation and $45^{\circ}$ orientation relative to the component axis. The declared surface quality is $10 \mu \mathrm{m}$. The results of sample measurements of M270 and M290 materials are shown in Figures 4 to 7.

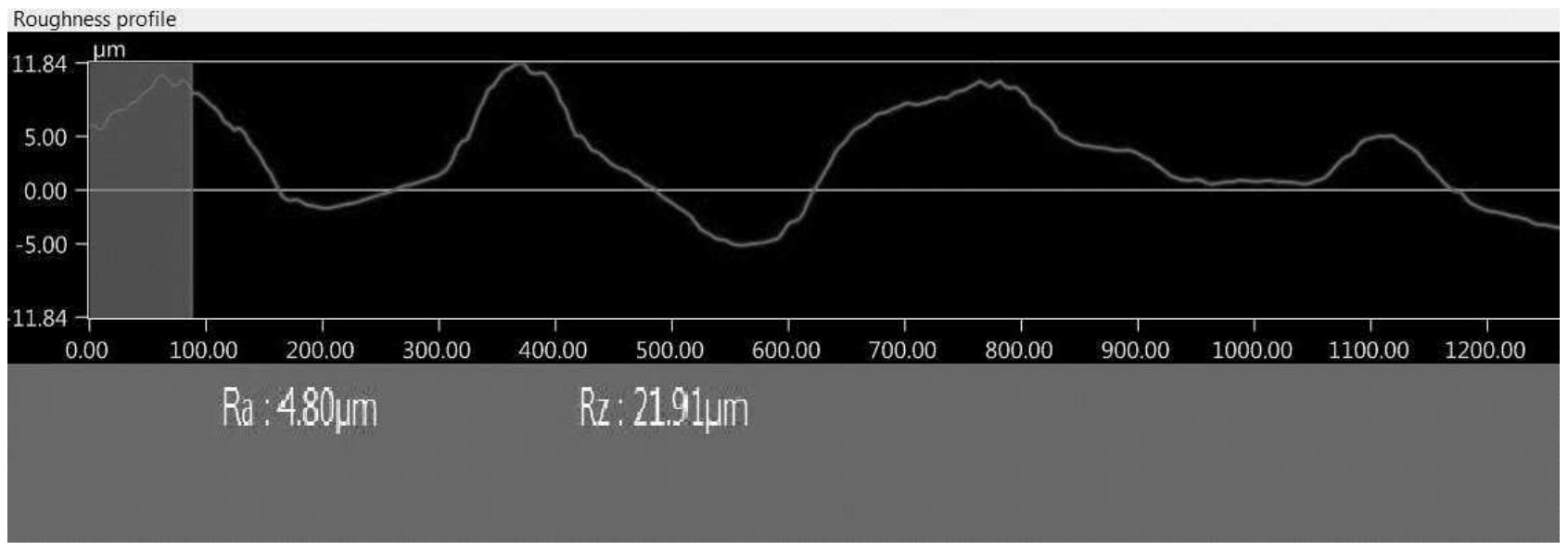

Fig. 4 Surface roughness profile of $M 270,45^{\circ}$

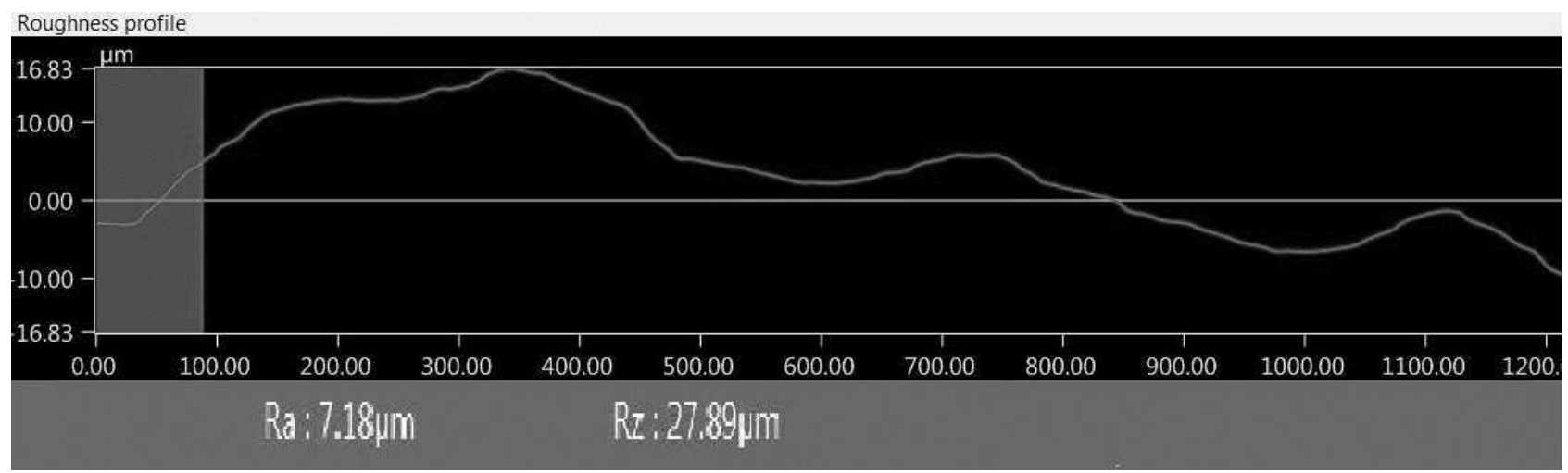

Fig. 5 Surface roughness profile of $M 270,0^{\circ}$

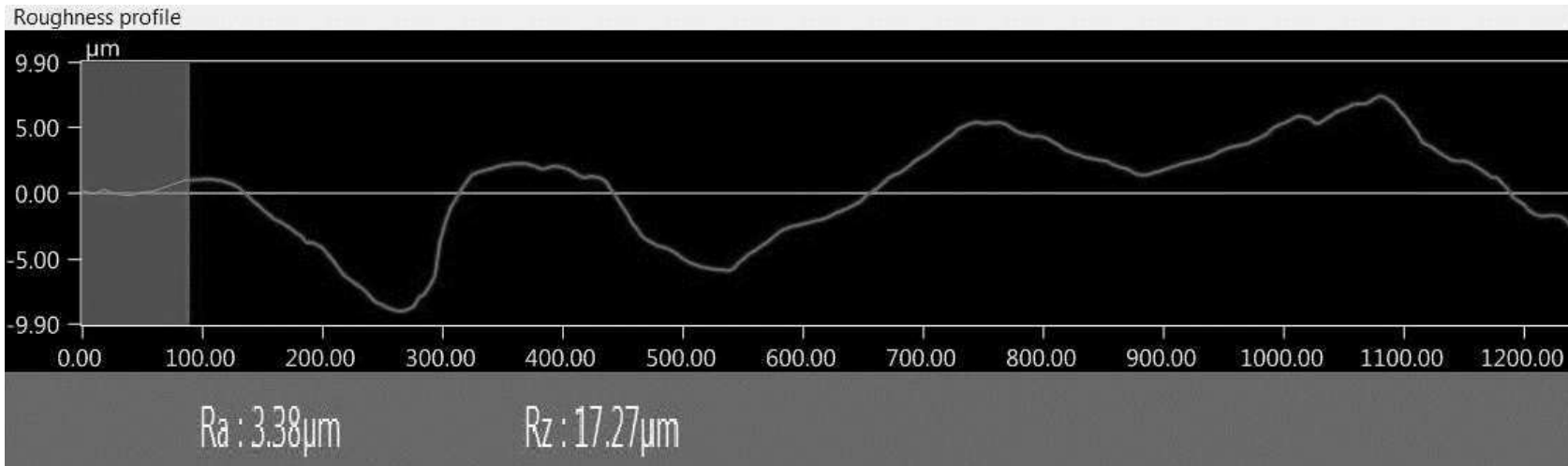

Fig. 6 Surface roughness profile of M 290, $45^{\circ}$ 


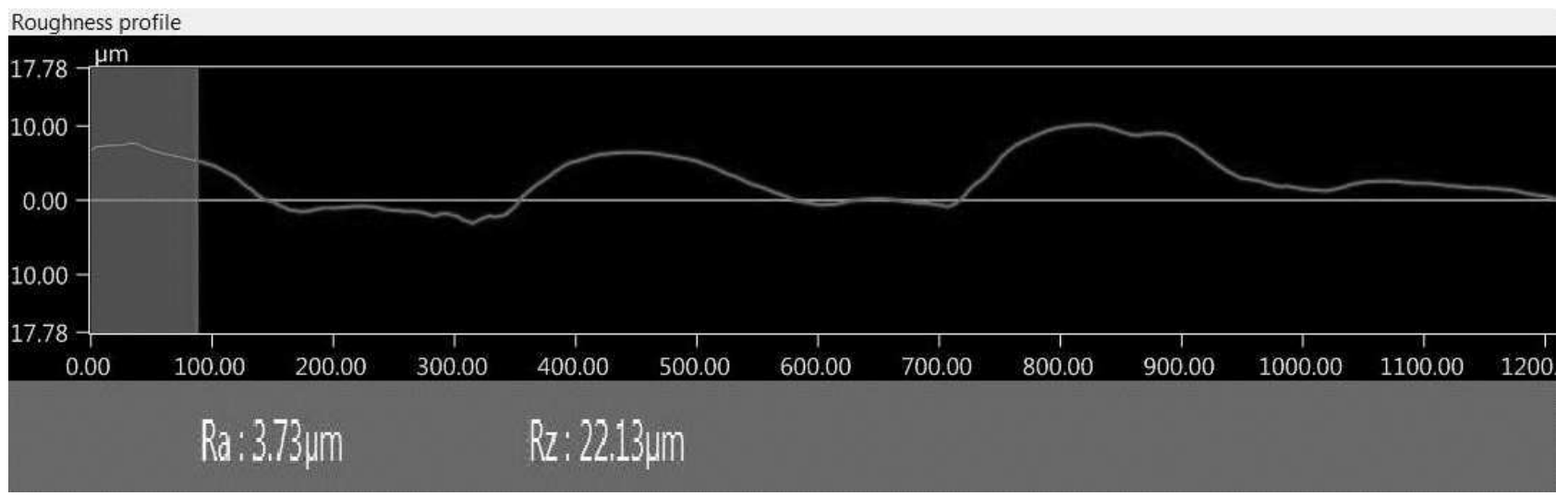

Fig. 7 Surface roughness profile of $M 290,0^{\circ}$

IN 718 is tested on the components printed in a horizontal plane parallel to the component axis. Measurement visualization is depicted in Figure 8. Achieving declared and better quality can be judged from the interpretation of results. All of the measurements shown exhibit surface quality with minimal variations. For the subsequent technical utilization, the Ra quality parameter is considered, which is further listed on the production drawing, possibly as one of the text or graphical attributes of the 3D documentation. At the same time, the Ra parameter is declared within the declared quality of $3 \mathrm{D}$ print outputs by the given method and is part of the material technology sheet of the method [13].

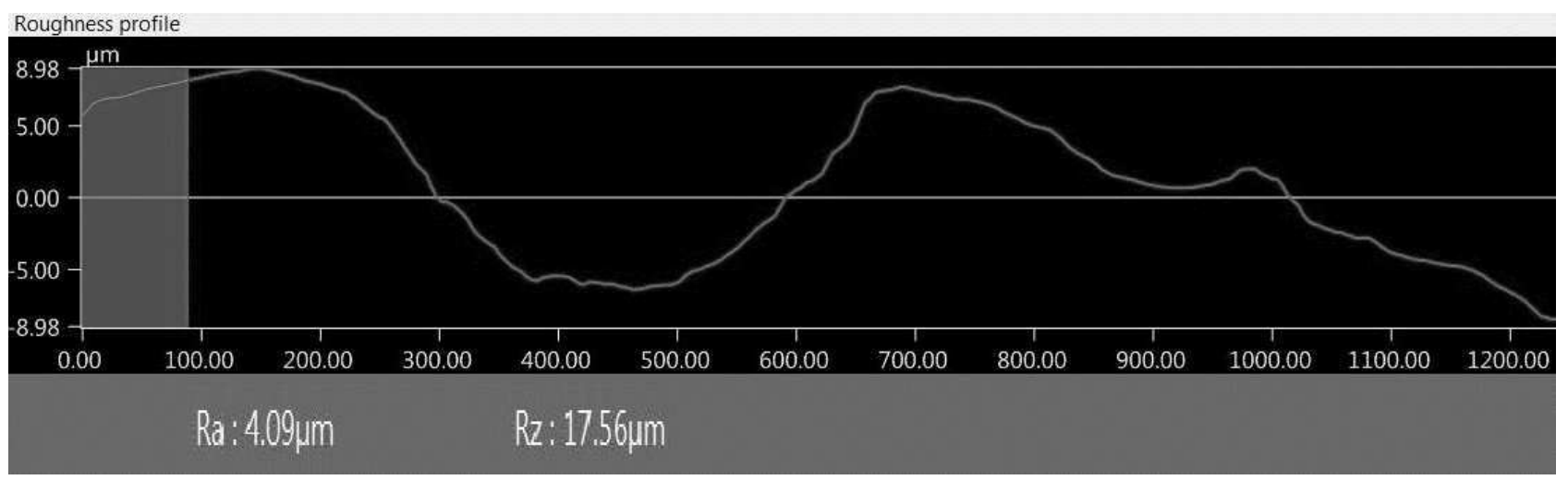

Fig. 8 Surface roughness profile of Inconel, $0^{\circ}$

\section{Conclusion}

By analyzing the samples, the input factors for determining the quality of the samples are verified. Dimensions and surface quality are considered as quality parameters. Three different materials are tested overall, and there are two different orientation of the printing layers relative to the axis determining the orientation of the product for each material. The dimensional characteristics are compared with the declared ISO 2768 - c accuracy table values and the statistical probability of reaching ISO 2768 - m, suitable for engineering use. The surface quality is determined by digital processing of the correspondingly enlarged surface image. The results of surface roughness measurement by digital microspopic sampling indicate a uniform distribution of inequalities. The measurement results are consistent with the stated quality of the production technology and better. When designing a component, it is possible to consider reliably the declared quality directly by manufacturing without the need for subsequent postprocessing. The influence of the orientation of the part during printing is significant for dimensional accuracy but not significant for surface quality.
These findings determine the input variables of topological optimization of the model in the preparation of the production technology. Attention to correcting a digital model can be focused on achieving the desired shape, dimensional accuracy.

\section{Acknowledgement}

This research was supported by the College of Polytechnics, Jihlava, Czech Republic, under Grant "Research on Preprocessor and Postprocessor Quality by a 3D Print Model”.

\section{References}

[1] MONKOVA, K., MONKA, P. (2017). Qualitative parameters of complex part produced by additive approach. In: 2017 8th International Conference on Mechanical and Aerospace Engineering (ICMAE) [online]. IEEE, 691-694 (2017).

[2] DAŇA, M., ZETKOVÁ, I., HANZL, P. (2019). The Influence of a Ceramic Recoater Blade on 3D 
Printing using Direct Metal Laser Sintering. Manufacturing Technology. 2019, 19(1), 23-28. DOI: 10.21062/ujep/239.2019/a/12132489/MT/19/1/23. ISSN 12132489.

[3] ZELTMANN, S. E., GUPTA, N., TSOUTSOS, N. G., MANIATAKOS, M., RAJENDRAN, J., KARRI, R. (2016). Manufacturing and security challenges in $3 D$ printing. Jom, 68(7), 1872-1881 (2016).

[4] CHUA, C. (2005). Rapid prototyping: principles and applications. 2nd ed. Hackensack: WorldScientific, 2005. ISBN 98-123-8120-1.

[5] GIBSON, I., D. W ROSEN a B. STUCKER. (2010). Additive manufacturing technologies: rapid prototyping to direct digital manufacturing. New York: Springer, c2010. ISBN 9781441911193.

[6] GASTEL, SJEF Van, (2016). Printing by the Rules. Mikroniek, Volume 5, 2016.

[7] M. CONTERO A C. PEDRO (2016). "Parametric CAD modeling: An analysis of strategies for design reusability," Computer-Aided Design, vol. 74, pp. 18-31, 2016.

[8] TAKAGISHI, K., UMEZU, S. Development of the Improving Process for the 3D Printed Structure, Scientific Reports 7, Article number: 39852 (2017).
[9] K. DVORAK AND L. ZARYBNICKA (2018). "Influence of the 3D Model and Technological Parameters on the Mechanical Properties of Fused Deposition Modeling 3D Products," International Journal of Mechanical Engineering and Robotics Research, Vol. 7, No. 4, pp. 415-421, July 2018. DOI: $10.18178 /$ ijmerr.7.4.415-421

[10] HANZL, P., ZETKOVÁ, I., KUČEROVÁ, L. (2019). Structural Changes and Microstructure of Maraging Steel Lattice Structures using Additive Manufacturing. Manufacturing Technology. 2019, 19(1), 37-41. DOI: 10.21062/ujep/241.2019/a/12132489/MT/19/1/37. ISSN 12132489.

[11] FOUSOVA, M., VALESOVA, V., VOJTECH, D. (2019). Corrosion of 3D-Printed AlSi9Cu3Fe Alloy. Manufacturing Technology. 2019, 19(1), 29-36. DOI: 10.21062/ujep/240.2019/a/12132489/MT/19/1/29. ISSN 12132489.

[12] KRIŠTOFOVÁ, P., KUBÁSEK, J., VOJTĚCH, D., PALOUŠEK, D., SUCHÝ, J. (2019). Microstructure of the Mg-4Y-3RE-Zr (WE43) Magnesium Alloy Produced by 3D Printing. $\mathrm{Ma}$ nufacturing Technology. 2019, 19(1), 89-94. DOI: 10.21062/ujep/249.2019/a/12132489/MT/19/1/89. ISSN 12132489.

[13] DAŇA, M., ZETKOVÁ, I., MACH, J. (2018). Mechanical properties of Inconel Alloy 718 produced by 3D printing using DMLS. Manufacturing Technology. 2018, 18(4), 559-562. ISSN 1213-2489. 